\title{
Study of subsurface eddy properties in northwestern Pacific Ocean based on an eddy-resolving OGCM
}

\author{
Anqi $X u^{1,2,3} \cdot$ Fei $\mathrm{Yu}^{1,2,3,4,5}$ (D) Feng Nan ${ }^{1,2,3}$ \\ Received: 15 May 2018 / Accepted: 31 January 2019 / Published online: 5 March 2019 \\ (C) The Author(s) 2019
}

\begin{abstract}
A method based on the Okubo-Weiss parameter was used to detect subsurface eddies (SSEs) with an eddy-resolving ocean general circulation model. Statistical analyses showed that SSEs are ubiquitous in the northwestern Pacific Ocean. Three regions were found to have high probability of SSE, which are as follows: the latitudinal band between $9^{\circ} \mathrm{N}$ and $17^{\circ} \mathrm{N}$, the Kuroshio extension region, and the area east of the Ryukyu Islands. Although surface eddies (SEs) were found distributed widely within the zonal band of the Subtropical Counter Current, few SSEs were found there. In contrast, few SEs were found to the east of The Philippines, whereas SSEs were abundant. The kinetic energy contained within SSE was found comparable in magnitude with that of SE. During 1993-2013, about 2569 and 2099 SSEs (at a depth of about $400 \mathrm{~m}$ ) were observed to be anticyclonic and cyclonic, respectively; thus, SSEs tended to be anticyclonic. The mean radius, lifespan, and propagation speed of SSE in this study were about $60 \mathrm{~km}, 50$ days, and $6.6 \mathrm{~cm} / \mathrm{s}$, respectively. The propagation speed showed a wave-like decrease with increasing latitude. Some long-lived SSEs were found to persist for longer than 4 months and to move thousands of kilometers. About $89 \%$ of SSEs were nonlinear for at least half their lifespan, which implies that SSE can trap interior fluid during translation. Trajectories revealed that SSEs propagate nearly due west with only small meridional deflection. The findings of this study will contribute to the enrichment of our knowledge regarding SSE in the northwestern Pacific Ocean.
\end{abstract}

Keywords Subsurface eddies · Eddy characteristics $\cdot$ Kinetic energy

\section{Introduction}

Mesoscale eddies are important in the transportation of oceanic heat, salt, freshwater, nutrient, and biological signatures. Mesoscale eddies can be classified as surface-intensified

Responsible Editor: Pierre F.J. Lermusiaux

Fei Yu

yuf@qdio.ac.cn

1 Institute of Oceanology, Chinese Academy of Sciences, Qingdao 266071, China

2 University of Chinese Academy of Sciences, Beijing 100049, China

3 CAS Key Laboratory of Ocean Circulation and Waves, Chinese Academy of Sciences, Qingdao 266071, China

4 Center for Ocean Mega-Science, Chinese Academy of Sciences, Qingdao 266071, China

5 Marine Dynamic Process and Climate Function Laboratory, Pilot National Laboratory for Marine Science and Technology (Qingdao), Qingdao 266237, China eddies and subsurface-intensified eddies based on the vertical distribution of their hydrographic signals. Subsurface eddies (SSEs), which represent a special class of ocean eddy, are characterized by having their core or maximum velocity in subsurface water (Gordon et al. 2002). The temperature and salinity properties of SSE are reasonably homogeneous but distinct from those of the surrounding waters (Johnson and McTaggart 2010; McWilliams 1985; Nauw et al. 2006). Generally, SSEs are triggered by instability of the undercurrent or subduction of mode water (Oka et al. 2009; Takikawa et al. 2005). Previous studies have proven that SSE can strongly influence intermediate or deeper ocean layers by affecting the subsurface circulation, pathways of water masses, and redistribution of heat, salt, and momentum (Andrade et al. 2014; Colas et al. 2012; Nan et al. 2017; Pelland et al. 2013). Unlike surface eddies (SEs), which can be characterized using satellite altimeter data, SSEs have weak surface expression, and they are poorly understood because of the lack of their systematic measurement (Chaigneau et al. 2011; Gordon et al. 2017; Johnson and McTaggart 2010). Most reported eddies have survived for a significant time (of the order 
of months) and traveled considerable distance (hundreds of kilometers) (Combes et al. 2015; Takikawa et al. 2005). Based on Argo float data and sporadic in situ observations, SSEs have been detected in numerous oceanic regions, e.g., as "Meddies" in the Mediterranean Sea (McDowell and Rossby 1978; Richardson et al. 2000), "Ruddies" in the Indian Ocean (Shapiro and Meschanov 1991), and "Cuddies" near the California Undercurrent (Collins et al. 2013; Kurian et al. 2011; Pelland et al. 2013). SSEs also exist in the eastern South Pacific Ocean associated with the Peru-Chile Undercurrent (Combes et al. 2015; Hormazabal et al. 2013; Johnson and McTaggart 2010; Thomsen et al. 2016). In contrast, research on SSE in the northwestern Pacific Ocean has been limited, and only a few examples have been observed.

The ocean circulation in the northwestern Pacific Ocean is characterized by a complex western boundary current. In the surface layer, the North Equatorial Current bifurcates into the northward-flowing Kuroshio and the southward-flowing Mindanao Current (MC) as it approaches the coast of The Philippines. A significant portion of the $\mathrm{MC}$ veers eastward at the southern tip of the island of Mindanao near $5^{\circ} \mathrm{N}$ to form the North Equatorial Countercurrent. In the latitudinal band of $18^{\circ}-24^{\circ} \mathrm{N}$, the North Pacific Subtropical Counter Current (STCC), which is a weak and shallow eastward current, penetrates into the open Pacific from $130^{\circ}-180^{\circ} \mathrm{E}$ (Chang and Oey 2014). Below the surface, the subsurface circulation is dominated by several important undercurrents. Beneath the MC and the Kuroshio, along the coast of The Philippines, are the southward-flowing Luzon Undercurrent and northwardflowing Mindanao Undercurrent, respectively $\mathrm{CH}$ and $\mathrm{Cui}$ 1989; Hu et al. 1991). The North Equatorial Undercurrent consists of three parallel eastward-flowing jets at the depth of approximately $500-1100 \mathrm{~m}$ along $9^{\circ} \mathrm{N}, 13^{\circ} \mathrm{N}$, and $18^{\circ} \mathrm{N}$. These jets typically have a core velocity of $3-5 \mathrm{~cm} / \mathrm{s}$, and they are spatially coherent from the western boundary across the North Pacific basin to about $120^{\circ} \mathrm{W}$ (Qiu et al. 2015).

Takikawa et al. (2005) detected SSE to the southeast of the Ryukyu Islands, which had thickness and width of $300 \mathrm{~m}$ and $100 \mathrm{~km}$, respectively. In December 2013, a subsurface lens of water from the Andaman Sea was captured in the Bay of Bengal (Gordon et al. 2017). Nan et al. (2017) detected an extra-large subsurface anticyclonic eddy with horizontal scale of $470 \mathrm{~km}$ in the Northwest Pacific subtropical gyre. Their analysis indicated that the SSE formed in the region of Subtropical Mode Water and, then, propagated westward for over $1500 \mathrm{~km}$. In general, these case studies of SSE have focused mainly on a single eddy found at a specific location or along a section. However, such observations of SSE cannot provide information about their spatial distribution or the roles they might play in the ocean. More importantly, most previous studies have focused on subsurface anticyclonic eddies (SSAEs) with low potential vorticity, while the characteristics of subsurface cyclonic eddies (SSCEs) remain unclear. The remainder of this paper is organized as follows: Section 2 briefly describes the model configuration and altimetry dataset used in this study. The eddy detection and tracking method is presented in Section 3. The properties of SSE, i.e., their occurrence frequency, kinetic energy, size, lifetime, propagation characteristics, polarity, and nonlinearity, are presented in Section 4. A summary of the results is provided in Section 5.

\section{Model and datasets}

The Oceanic General Circulation Model for the Earth Simulator (OFES) used in this study is based on the Modular Ocean Model ver. 3 developed by the Geophysical Fluid Dynamic Laboratory of the National Oceanic and Atmospheric Administration (Masumoto et al. 2004; Sasaki et al. 2008). The model utilizes the $\mathrm{z}$-level coordinate in the vertical, and it solves threedimensional primitive equations in spherical coordinates under the Boussinesq and hydrostatic approximations. Its domain extends from $75^{\circ} \mathrm{S}$ to $75^{\circ} \mathrm{N}$, excluding the Arctic region, with $0.1^{\circ}$ horizontal grid spacing. The vertical level spacing varies from $5 \mathrm{~m}$ at the surface to $330 \mathrm{~m}$ near the bottom. The model topography is generated using $1 / 30^{\circ}$ bathymetry data provided by the Ocean Circulation and Climate Advanced Modelling project. For further details regarding the configuration and evaluation of this model, readers are referred to Masumoto et al. (2004) and Sasaki et al. (2008).

The OFES outputs have been analyzed in numerous earlier studies (Aoki et al. 2007; Chen et al. 2010; Chiang and Qu 2013; $\mathrm{Qu}$ et al. 2012). The results have demonstrated the promising capability of the model in representing realistic variability of different spatial and temporal scales in the ocean, including western boundary currents, mesoscale eddy generation near strong current systems, as well as appropriate water masses in the world's ocean. This study analyzed snapshot (3d) model outputs for the domain of the northwestern Pacific Ocean $\left(0^{\circ}-60^{\circ} \mathrm{N}\right.$, $120^{\circ}-180^{\circ} \mathrm{E}$ ) from January 1993 to December 2013.

Two types of satellite data were used to validate the OFES data. Sea level anomaly (SLA) data used in this study were obtained from the French Archiving, Validation, and Interpolation of Satellite Oceanographic (AVISO) data project, which merges the measurements of Jason, TOPEX/POSEIDON, Envisat, GFO, ERS, and Geosat altimeters. The merged data are interpolated onto a global grid with $1 / 4^{\circ}$ resolution, and they are archived in weekly-averaged frames. The entire dataset covers the period 1993-present; however, only the data from 1993 to 2013 were used in this study.

The 4th release of the trajectories of mesoscale eddies produced by the Collecte Localisation Satellites/Data Unification and Altimeter Combination System team is based on the DT2014 daily "two-sat-merged" SLA fields posted online by AVISO for the 22-year period from January 1993 to April 2015. The eddy dataset provides the amplitude, radius scale, 
centroid, date of starting point, and number of points along the eddy tracks. The trajectories in this new version of the eddy dataset are available with time steps of 1 day, and only eddies with a lifetime of four weeks or longer are counted. In the new eddy dataset, rather than defining eddies by the outermost closed contour of sea surface height, as in the previous three eddy datasets, each eddy is defined based on connected pixels that satisfy the specified criteria. The procedure is a modified version of the method presented by Williams et al. (2011). A description of the implementation of the eddy identification procedure can be found on the following website: http:// wombat.coas.oregonstate.edu/eddies/index.html. In the current study, we used trajectory data of mesoscale eddies for the 21-year period from January 1993 to December 2013.

\section{Eddy detection and tracking method}

Several methods have been developed for detecting eddies from satellite altimetry and model simulations. Among these, the most popular involve the closed contour of sea surface height (Chaigneau et al. 2009; Chelton et al. 2011) or the Okubo-Weiss $(\mathrm{O}-\mathrm{W})$ parameter (Isern-Fontanet et al. 2003, 2004, 2006; Okubo 1970; Weiss 1991) owing to its simplicity and computational efficiency. This study used the objective criterion of the $\mathrm{O}-\mathrm{W}$ parameter because it can identify eddies at desired depth levels or isopycnal surfaces of model solutions. The $\mathrm{O}-\mathrm{W}$ parameter $(\mathrm{W})$ is defined as:

$\mathrm{W}=S_{n}^{2}+S_{s}^{2}-\zeta^{2}$,

where $S_{n}=\frac{\partial u}{\partial x}-\frac{\partial v}{\partial y}$ and $S_{s}=\frac{\partial v}{\partial x}-\frac{\partial u}{\partial y}$ are the normal and shear components of strain, respectively, and $\zeta=\frac{\partial v}{\partial x}-\frac{\partial u}{\partial y}$ is the relative vorticity. For horizontally nondivergent flow in the ocean, $\mathrm{W}$ reduces to $4\left(\frac{\partial u^{2}}{\partial x}+\frac{\partial v}{\partial x} * \frac{\partial u}{\partial y}\right)$. The $\mathrm{W}$ contour search is typically defined as -0.2 times the standard deviation (Isern-Fontanet et al. 2003; Pasquero et al. 2001) or taken as a constant (Chelton et al. 2007). Considering the different depth levels of model data, the contour search in this study was performed using a specified threshold value $\left(\mathrm{W}_{0}=-\right.$ $0.2 \sigma \mathrm{w})$. Here, $\sigma \mathrm{w}$, which represents the standard deviation of the $\mathrm{W}$ field, was calculated at each time step for the selected domain and depth to obtain the threshold $\mathrm{W}_{0}$. Parameter $\mathrm{W}$ can be used to separate the flow into the following different regions: a vorticity-dominated region $\left(\mathrm{W}<-\mathrm{W}_{0}\right)$, a straindominated region $\left(\mathrm{W}>-\mathrm{W}_{0}\right)$, and a background field $(|\mathrm{W}| \approx$ $\mathrm{W}_{0}$ ). Regions, where rotation dominates deformation, have negative $\mathrm{W}$ values. To reduce the $\mathrm{W}$ noise, the $\mathrm{W}$ field was first smoothed with half-power filter cutoffs of $1.5^{\circ} \times 1.5^{\circ}$. Only those cases for which the $\mathrm{W}$ contour enclosed at least 40 pixels, equivalent to an area of about $50 \mathrm{~km}^{2}$, were considered. To be counted as an eddy, each closed contour had to pass an eddy shape test, which is described in detail by Kurian et al. (2011). The eddy shape error (anomaly from a fitted circle) was calculated for each closed contour. In this study, only those closed contours with a shape error of $<70 \%$ were defined as eddies. Vorticity was used to differentiate cyclonic and anticyclonic eddies. In the deep layer, eddy velocity is very weak and the accuracy of the $\mathrm{O}-\mathrm{W}$ method is decreased. Thus, only eddies with average velocity $>5 \mathrm{~cm} / \mathrm{s}$ were counted in this study. This criterion has little or no effect on eddy detection in the upper layer, whereas it improves the accuracy of eddy detection in the deep layer. Those closed contours that passed all the tests outlined previously were accepted as eddies. Figure 1 shows that the $\mathrm{W}$ fields display a patchy distribution. Generally, close correspondence is evident between the detected regions (blue and red circles) and closed streamlines; however, some closed streamline domains are not associated directly with detected regions and vice versa. This could be the result of the strict definition of eddies in terms of their shape and size adopted in this analysis.

Eddies were detected at each level from the surface to about 2000-m depth. Having determined the distribution of eddies at all depth levels during 1993-2013, it was necessary to distinguish SSEs from surface eddies (SEs). Generally, SSEs have a very weak or nonexistent signal at the sea surface. It should be stressed that in distinguishing SSEs from SEs, only those eddies with their entire body beneath the depth of $45 \mathrm{~m}$ were counted as SSEs, i.e., those that could not be detected in the upper eight layers of the model data. Consequently, this study ignored some intrathermocline eddies that have their core within the thermocline and sometimes exhibit weak expression at the surface. Figure 2 shows the $\mathrm{W}$ vertical profile of an anticyclonic SSE to the east of Taiwan, and its horizontal distribution of the $\mathrm{W}$ parameter and relative vorticity can be found in Fig. 1. After the eddies were identified for each time step and classified as either SSE or SE using the algorithm described previously, an automated tracking procedure based on connected pixels that satisfy specified criteria was applied to determine the trajectories of the SSE at different depth levels. The center location of each identified eddy was defined as the centroid of the outermost closed contour of $\mathrm{W}_{0}$.

To illustrate the model configuration, the eddy kinetic energy (EKE) at the surface from the OFES output is compared in Fig. 3 with that calculated from satellite data. Here, EKE is defined as $\mathrm{EKE}=\left(u^{\prime 2}+v^{\prime 2}\right) / 2$, where $u^{\prime}$ and $v^{\prime}$ are the zonal and meridional velocity anomalies, respectively. The parameters $u^{\prime}$ and $v^{\prime}$ can be computed from the SLA maps as follows: $\mathrm{u}^{\prime}=-\frac{g}{f} \frac{\partial(S L A)}{\partial y}$ and $\mathrm{v}^{\prime}=\frac{g}{f} \frac{\partial(S L A)}{\partial x}$, where $g$ is the acceleration due to gravity and $f$ is the Coriolis parameter. In the OFES data, $\mathrm{u}^{\prime}$ and $\mathrm{v}^{\prime}$ are defined as $\mathrm{u}^{\prime}=u-\bar{u}$ and $\mathrm{v}^{\prime}=v-\bar{v}$, where $\bar{u}$ and $\bar{v}$ denote the 

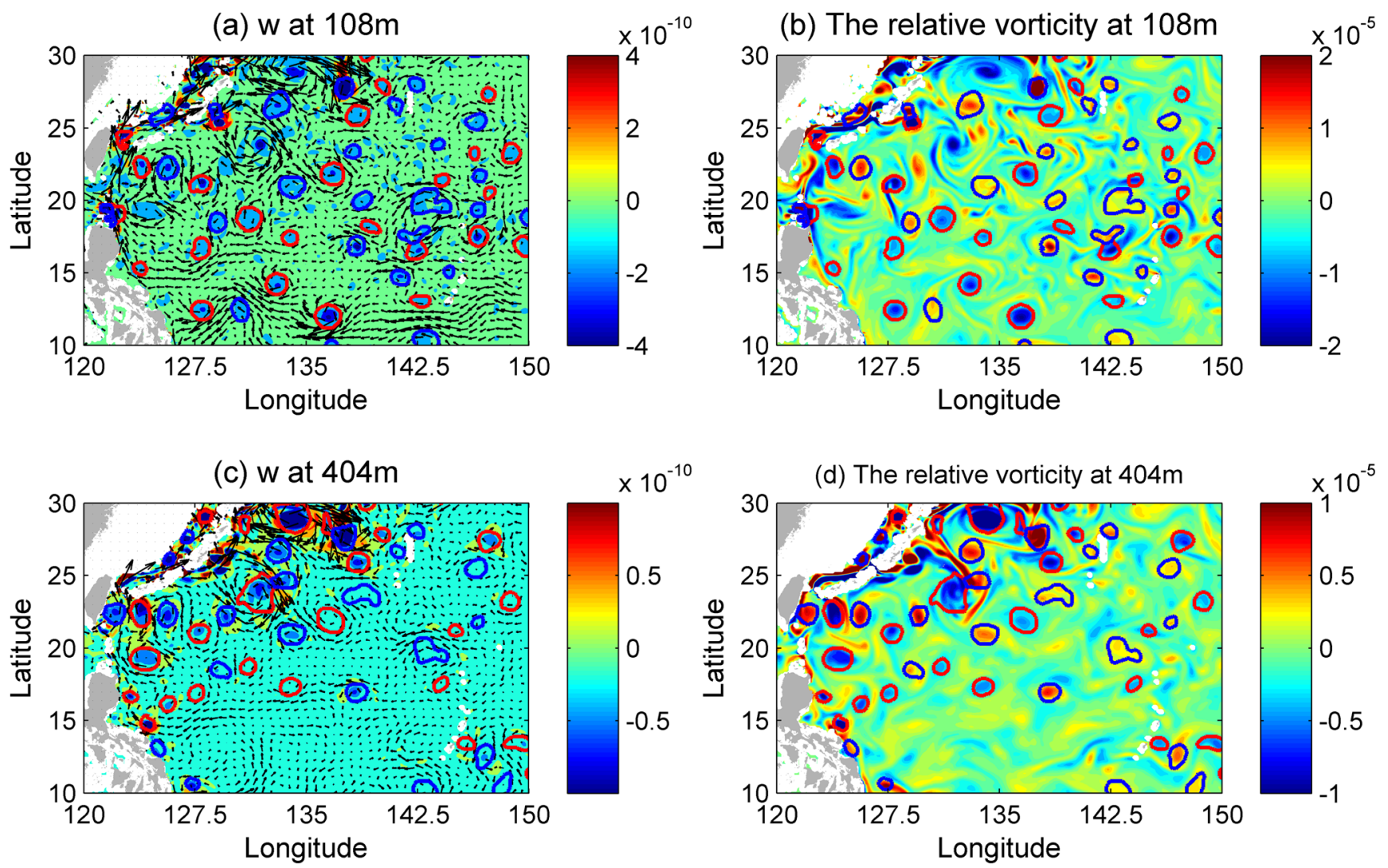

Fig. 1 Distribution of (a) the W parameter and (b) the relative vorticity at depth of $108 \mathrm{~m}$ on 29 June 2009. (c) and (d) are the same as (a) and (b) but at the depth of $404 \mathrm{~m}$. Also shown are velocity vectors and detected anticyclonic (red circles) and cyclonic (blue circles) regions

Fig. 2 Vertical $\mathrm{W}$ distribution of a subsurface eddy along $23.05^{\circ} \mathrm{N}$ on 29 June 2009. Black contour $\left(\mathrm{W}=\mathrm{W}_{0}\right)$ denotes region that passed all the eddy tests

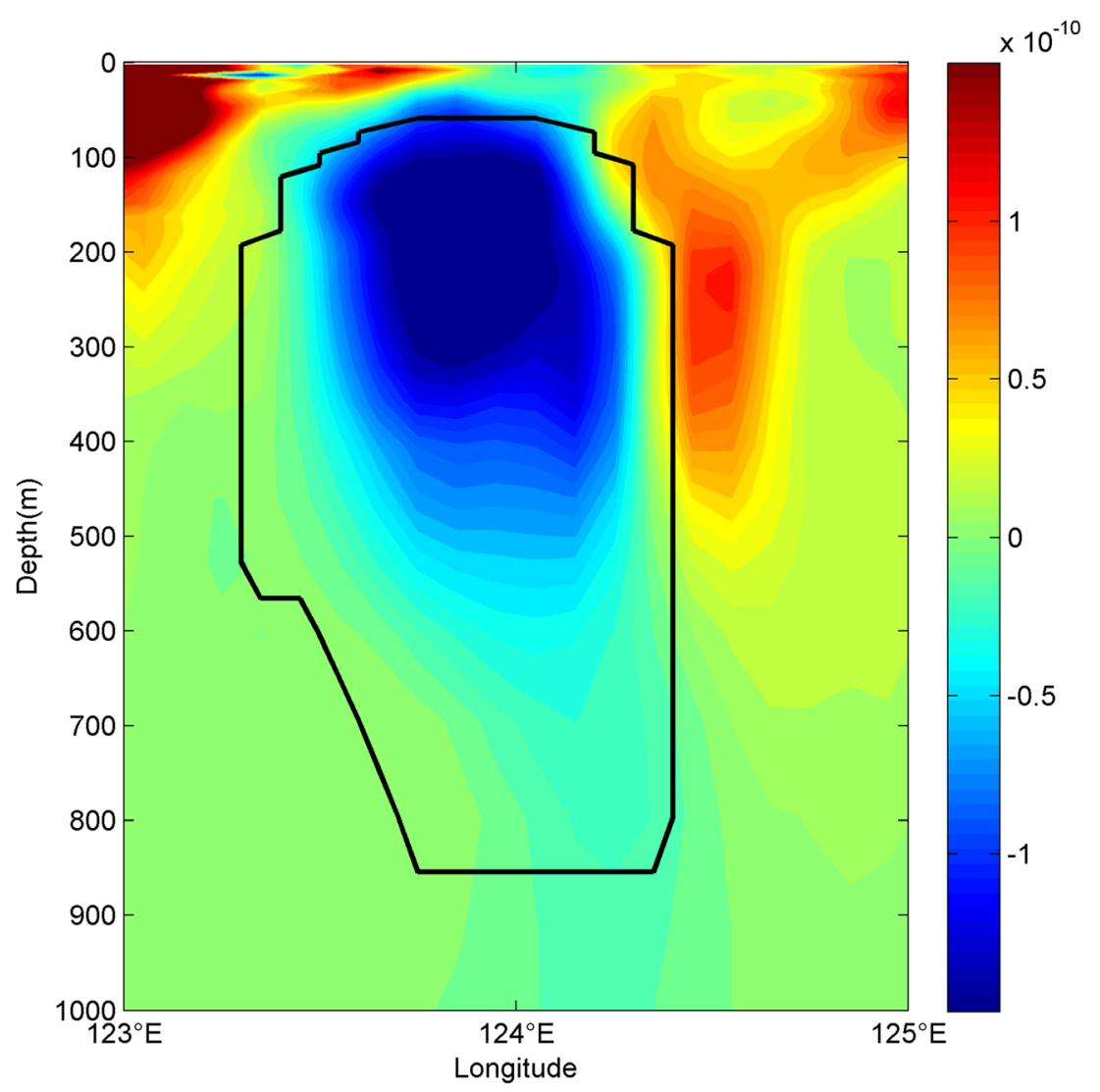




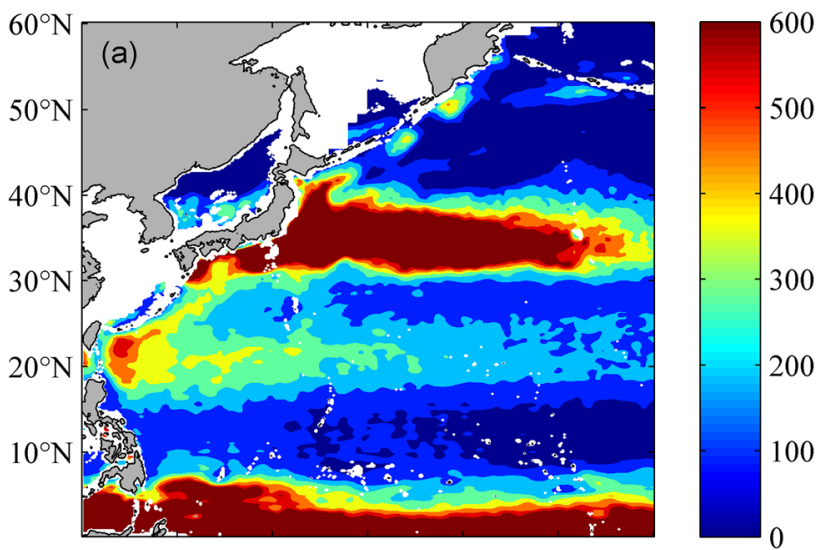

$120^{\circ} \mathrm{E} \quad 130^{\circ} \mathrm{E} \quad 140^{\circ} \mathrm{E} \quad 150^{\circ} \mathrm{E} \quad 160^{\circ} \mathrm{E} \quad 170^{\circ} \mathrm{E} \quad 180^{\circ} \mathrm{E}$

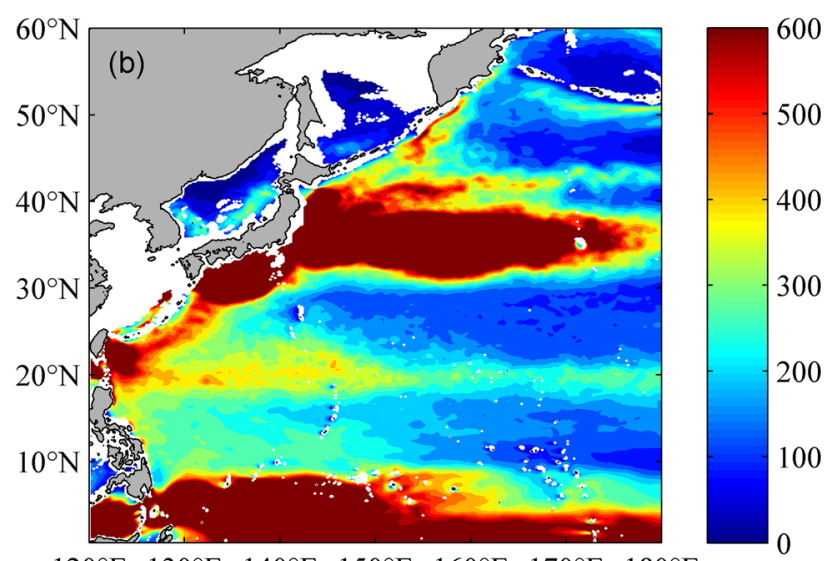

$120^{\circ} \mathrm{E} \quad 130^{\circ} \mathrm{E} \quad 140^{\circ} \mathrm{E} \quad 150^{\circ} \mathrm{E} \quad 160^{\circ} \mathrm{E} \quad 170^{\circ} \mathrm{E} \quad 180^{\circ} \mathrm{E}$

Fig. 3 Time-averaged eddy kinetic energy (unit $\mathrm{cm}^{2} / \mathrm{s}^{2}$ ) at the surface derived from (a) satellite data and (b) model data

average zonal and meridional velocity, respectively, of the corresponding month from 1993 to 2013. It is important to stress that point-wise comparison between the model EKE and altimetry-derived EKE is meaningless because of the difference in spatial resolution; therefore, we considered the temporal average of EKE from 1993 to 2013. The amplitude and spatial structure of the model mean EKE compare reasonably well with those derived from satellite data, i.e., both show maxima in the region of the Kuroshio extension and STCC. To verify that our detection method is effective, the frequencies of SE obtained from the AVISO eddy dataset and OFES data are shown in Fig. 4a,b, respectively. Eddy frequency was defined as the percentage of time that a point was located within a cyclonic or anticyclonic eddy. For example, eddy frequency at a specific location was considered about $10 \%$ if occupied by eddies for 10 out of 100 days. The spatial distribution of frequency of SE derived from the satellite data is similar in pattern to the OFES result, although it is slightly higher, which might be a function of different data resolution. In regions characterized with instabilities of background currents, such as the STCC and Kuroshio extension, SEs are found especially abundant.

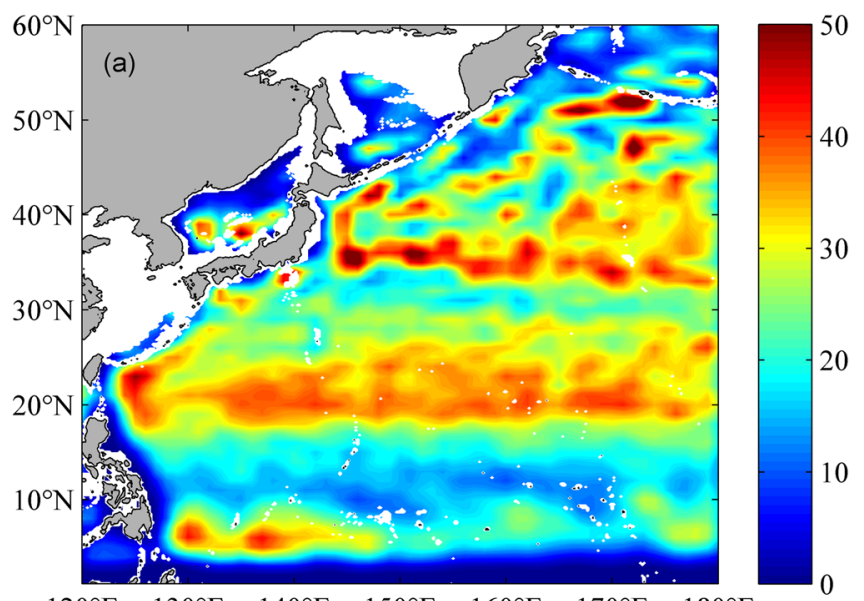

$120^{\circ} \mathrm{E} \quad 130^{\circ} \mathrm{E} \quad 140^{\circ} \mathrm{E} \quad 150^{\circ} \mathrm{E} \quad 160^{\circ} \mathrm{E} \quad 170^{\circ} \mathrm{E} \quad 180^{\circ} \mathrm{E}$

\section{Eddy characteristics}

\subsection{Eddy frequency}

It should be stressed that calculating the frequency of SSE at a fixed depth level might produce an underestimate because the depth ranges of SSE vary haphazardly. To calculate SSE frequency precisely, the time series of eddy vertical distribution at each grid point of model data was extracted. Figure 5 illustrates a simple example of a SSE passing a location, and, to provide a simple and effective numerical computation method, we used the Arabic numerals $-1,1$, and 0 to represent the area of an anticyclonic eddy, cyclonic eddy, and no rotation, respectively. Comparison of the frequency of SE and SSE (Fig. 6a,b) reveals the interesting phenomenon that the spatial distribution of SSE is significantly different from that of SE. High frequency of SSE is featured in several areas, including the latitudinal band between $9^{\circ} \mathrm{N}$ and $17^{\circ} \mathrm{N}$, area east of the Ryukyu Islands, and Kuroshio extension region. In addition, observations have proven the existence of SSE within our study area (Chiang et al. 2015; Nan et al. 2017; Takikawa et al. 2005; Zhang et al. 2015; Zhang et al. 2017). In the

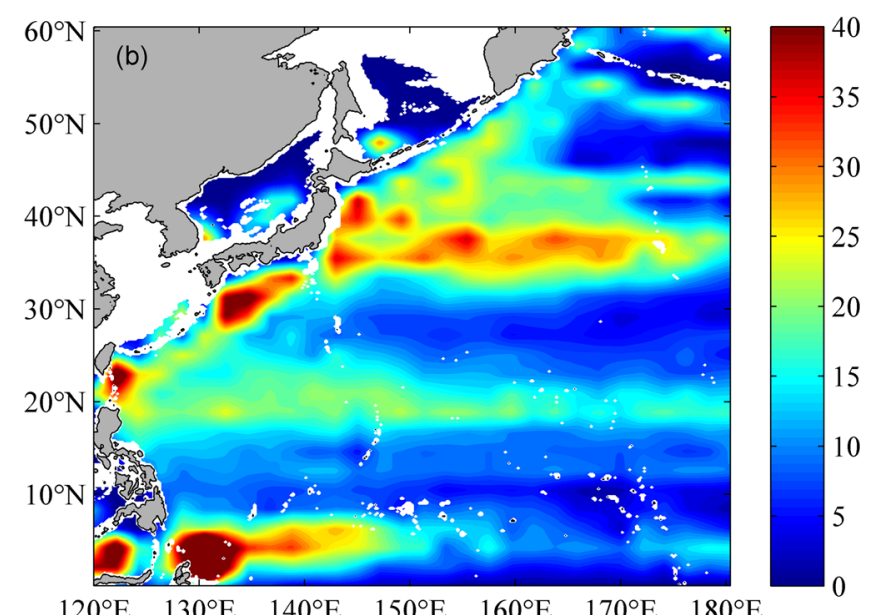

Fig. 4 Comparison of frequency (\%) of surface eddies between (a) the 4th eddy dataset and (b) the OFES result 
Time series

00000000000000000000

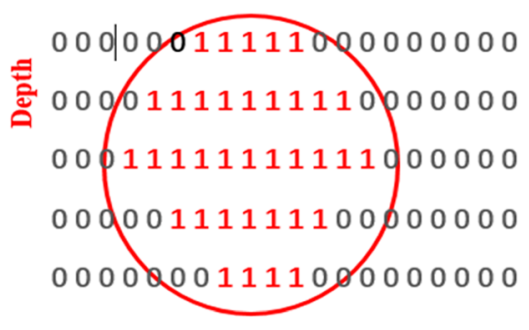

Fig. 5 Simple example illustrating the process of a subsurface eddy passing a point. Arabic numerals 1 and 0 represent area of cyclonic eddy and of no rotation, respectively

\section{Surface eddies}
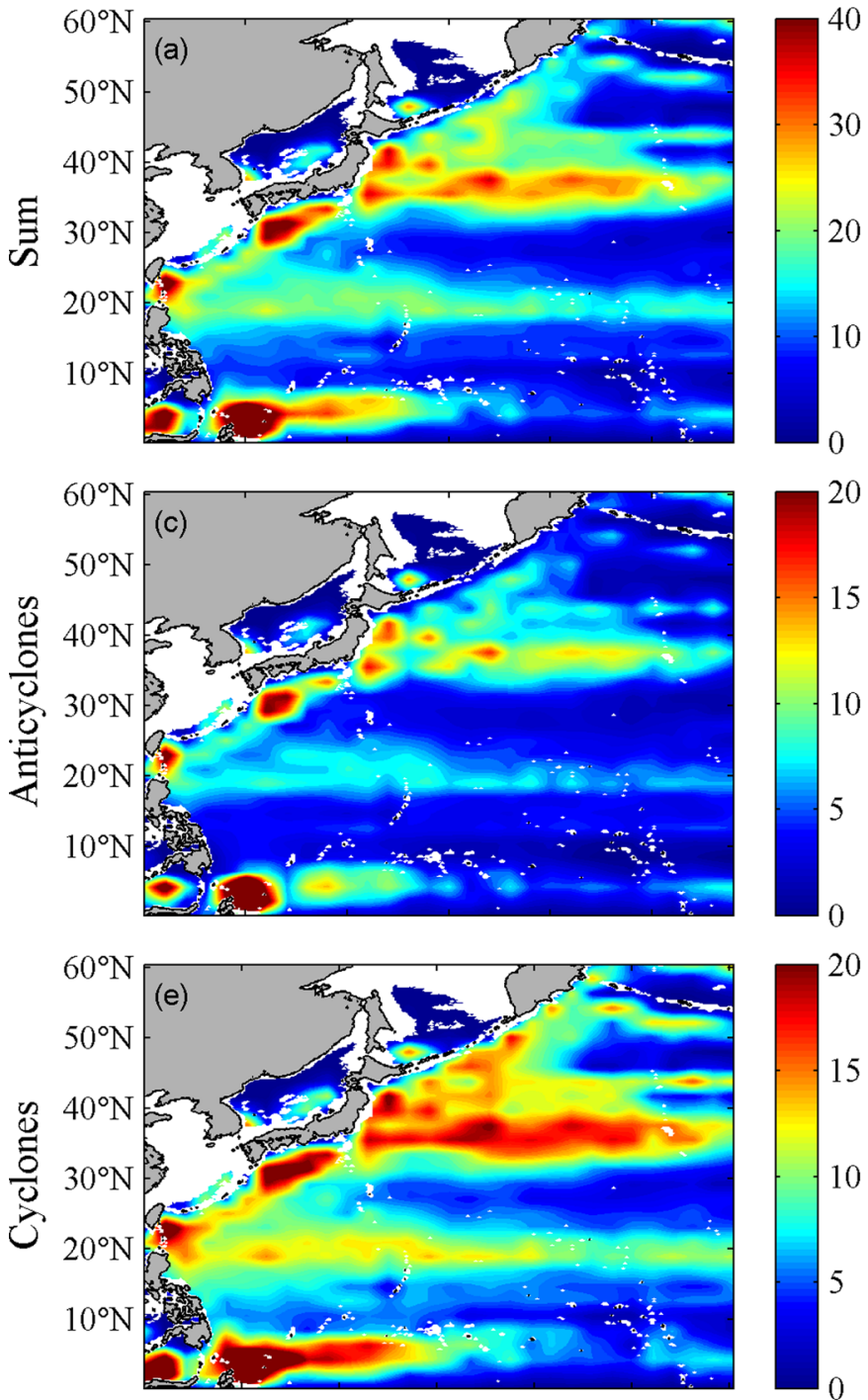

$120^{\circ} \mathrm{E} 130^{\circ} \mathrm{E} 140^{\circ} \mathrm{E} 150^{\circ} \mathrm{E} 160^{\circ} \mathrm{E} 170^{\circ} \mathrm{E} 180^{\circ} \mathrm{E}$

Fig. 6 Frequency (\%) of surface eddies (left) and subsurface eddies (right). Upper row shows total frequency of surface and subsurface eddies. Comparison of anticyclonic surface and subsurface eddies is latitudinal band of $9^{\circ}-17^{\circ} \mathrm{N}$, the frequency of SSE is noticeably elevated, especially in the area to the east of The Philippines where it can reach $16 \%$; however, the frequency of SE in this band is comparatively low (about 5\%). In the region of the STCC, the opposite is true, as shown in Fig. 6. The STCC region is rich in SE, i.e., the eddy frequency can reach about $25 \%$. Interestingly, with frequency of only about $2 \%$, SSEs are rare in this area. Previous studies have shown that the STCC is baroclinically unstable (Qiu 1999), and it has been proven using satellite data that SEs in the STCC region are abundant (Yang et al. 2013). In the region of the Kuroshio extension and to the east of the Ryukyu Islands, SE and SSE occur frequently, whereas SSEs are observed rarely to the south of $8^{\circ} \mathrm{N}$, except to the east of The Philippines. Generally, SEs are more likely to be cyclonic, whereas this

Subsurface eddies
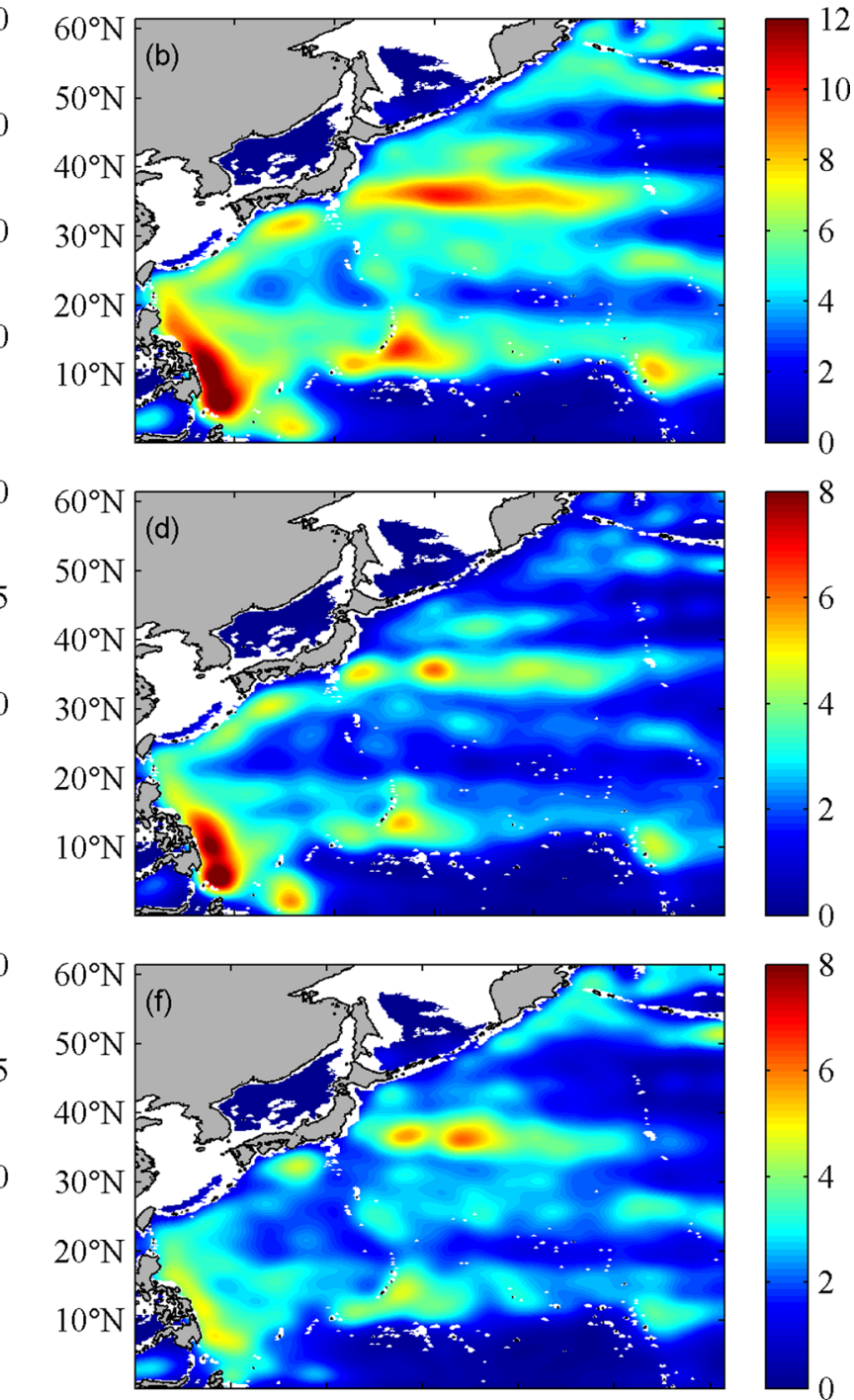

$120^{\circ} \mathrm{E} 130^{\circ} \mathrm{E} 140^{\circ} \mathrm{E} 150^{\circ} \mathrm{E} 160^{\circ} \mathrm{E} 170^{\circ} \mathrm{E} 180^{\circ} \mathrm{E}$

shown in the middle row. The lower row is the same as the middle row but for cyclonic eddies. Here, eddy frequency is the percentage of time when at least one eddy was passing the location 


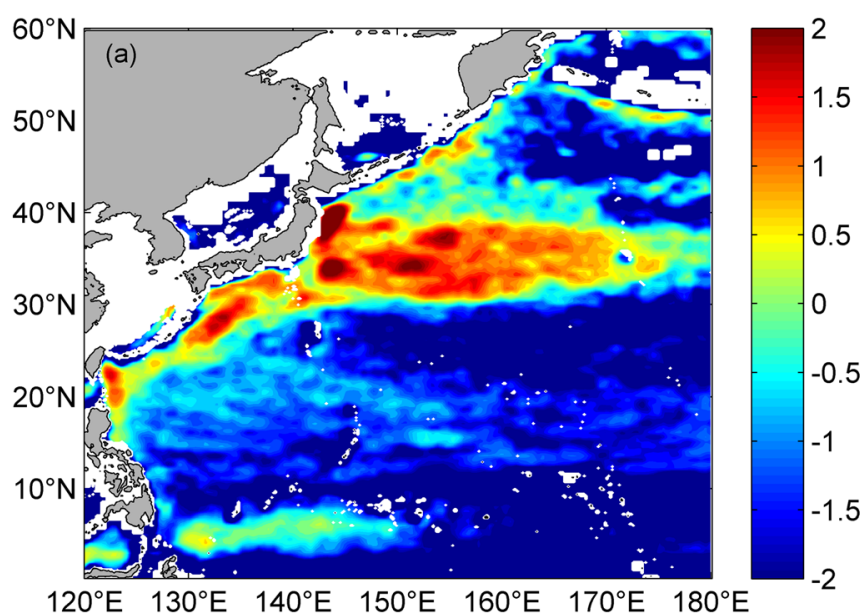

Fig. 7 Comparison of kinetic energy (unit $\mathrm{m}^{3} / \mathrm{s}^{2}$ ) between (a) surface eddies and (b) subsurface eddies. The kinetic energy here is calculated by averaging the vertical integral of EKE within SSE at each time step

is not the case for SSE. The frequency of SSAE displays a rather similar but more striking pattern than that of SSCE. The frequencies of SSAE and SSCE are shown in Fig. 6d,f, respectively. It can be seen that SSAE is observed more frequently than SSCE in areas to the east of The Philippines and the Ryukyu Islands. In the Kuroshio extension region, the frequency of SSAE is almost the same as that of SSCE.

\section{Lifetime $>=30$ days}

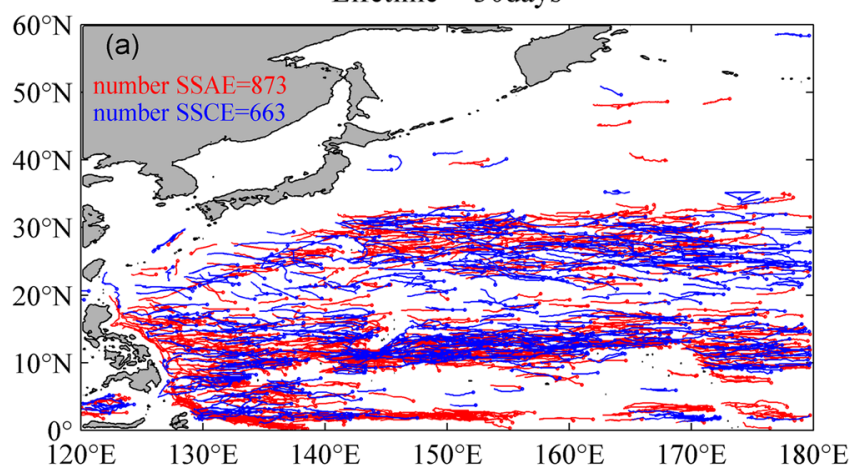

Lifetime $>=90$ days

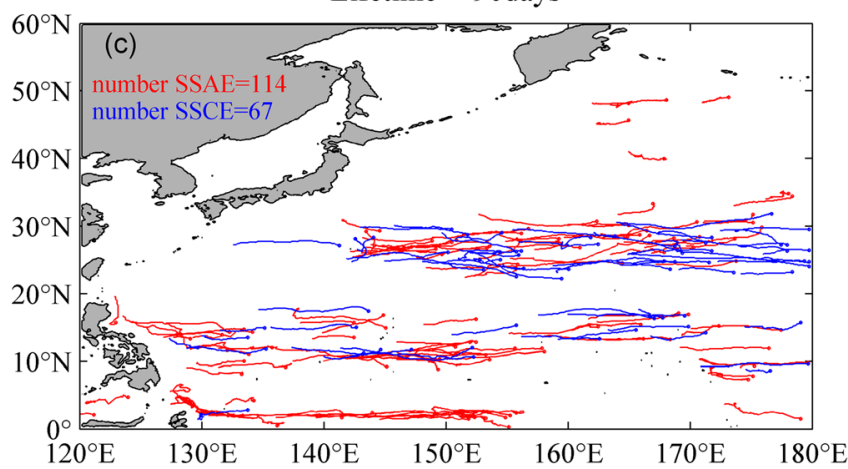

Fig. 8 Trajectories of subsurface anticyclonic eddies (SSAE; red lines) and subsurface cyclonic eddies (SSCE; blue lines) over the 21-year period 1993-2013 for (a) lifetime $\geq 30$ days, (b) lifetime $\geq 60$ days, (c)

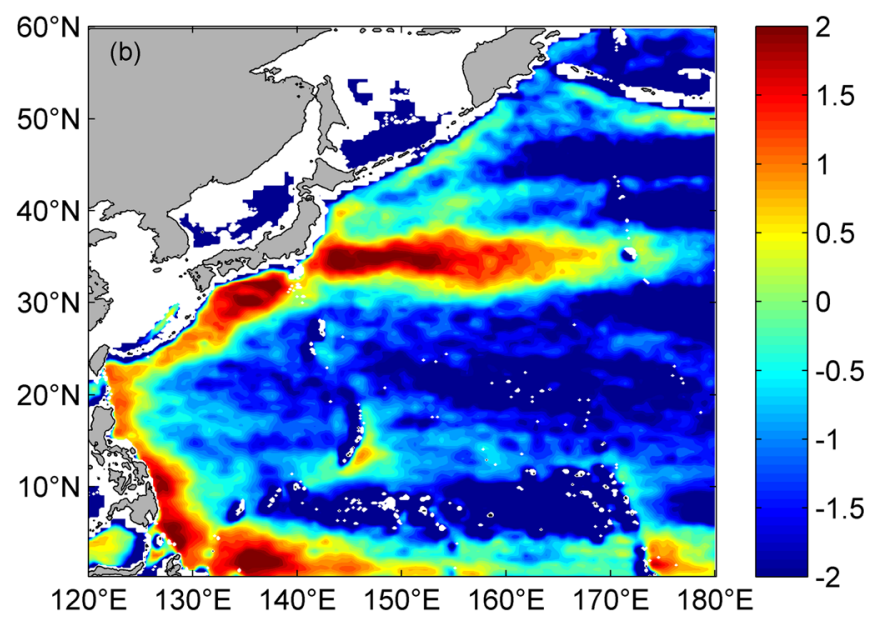

during 1993-2013, and, to depict the characteristics of the spatial distribution more intuitively, we provide the picture after taking the logarithm of the integral kinetic energy

Generally, long-lived or transitory but frequently occurring eddies might lead to high values of frequency at a specific location. Several mechanisms could be responsible for the different eddy frequencies in these regions, e.g., interaction of large-scale currents with bottom topography, coastlines, or islands, wind forcing, vorticity input from wind stress curl, vorticity conservation, and instability of coastal currents.

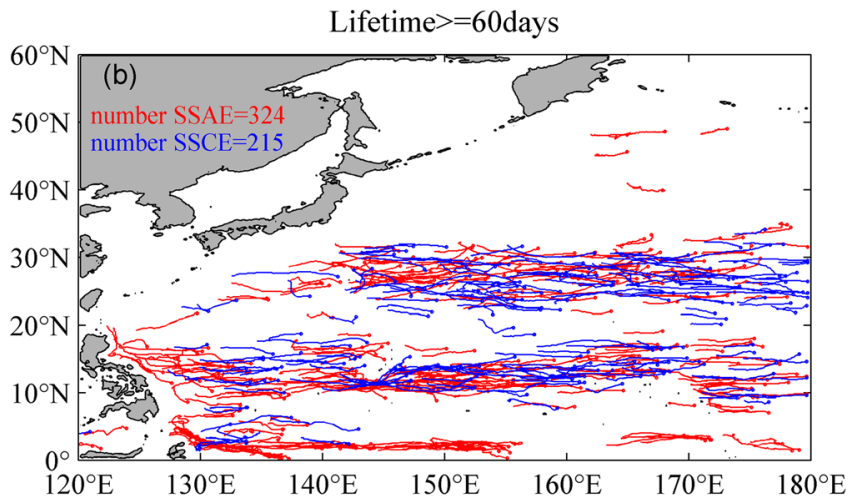

Lifetime $>=120$ days

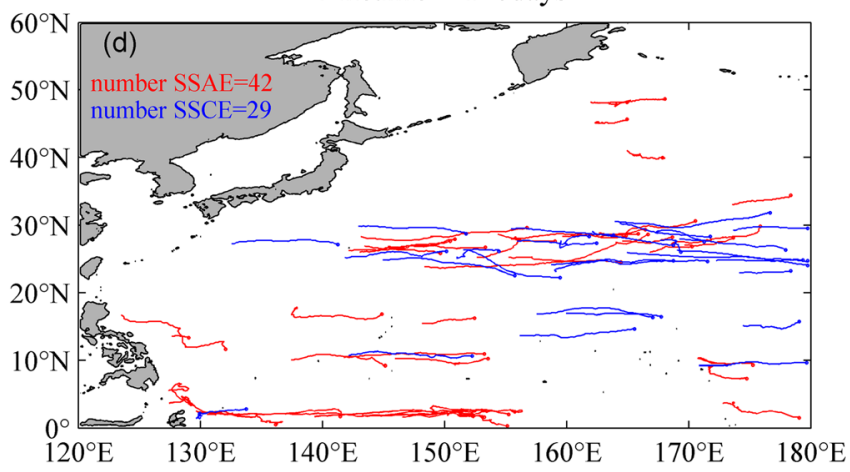

lifetime $\geq 90$ days, and (d) lifetime $\geq 120$ days. Numbers of SSAE and SSCE are labeled in the upper left corner of each map 

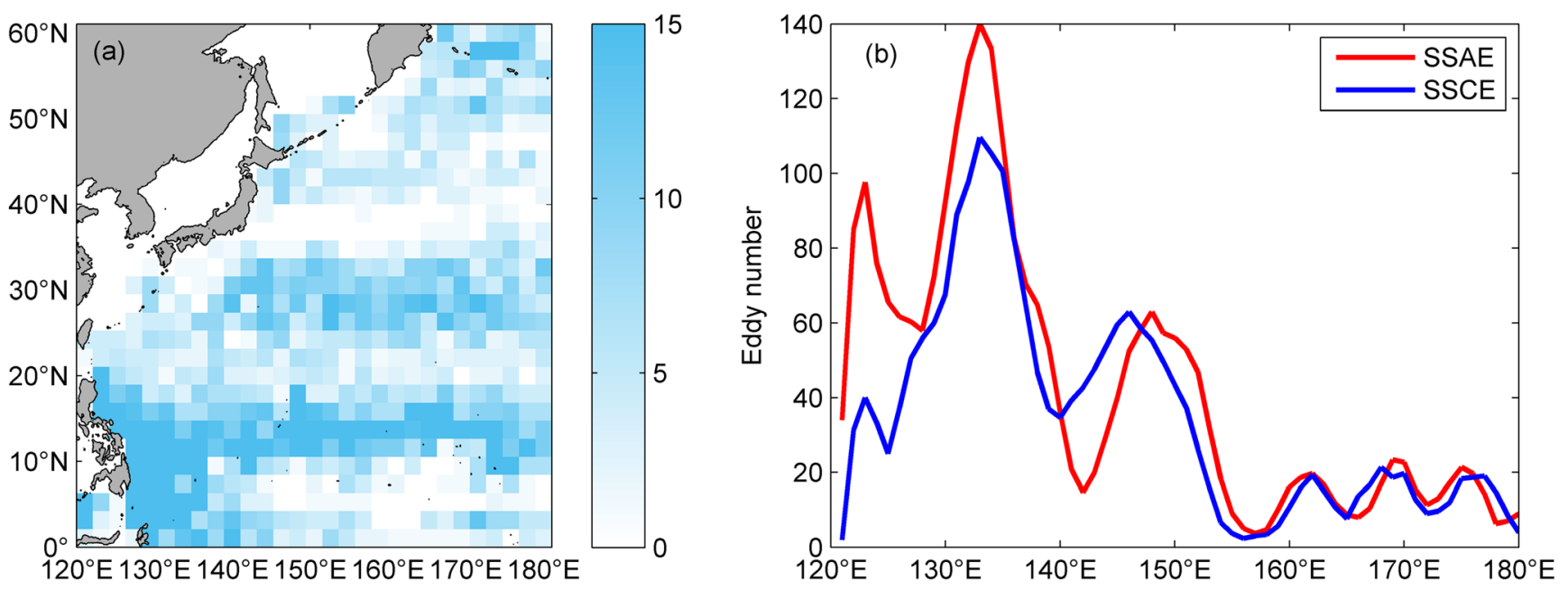

Fig. 9 (a) Number of all detected subsurface eddies (SSE) originating in each $2^{\circ} \times 2^{\circ}$ region during 1993-2013. (b) Numbers of subsurface anticyclonic eddies (SSAE; red line) and subsurface cyclonic eddies (SSCE; blue line) with lifetime $>30$ days at different latitudes

\subsection{Kinetic energy of SSE}

The kinetic energy of mesoscale eddies is larger than the mean current in the ocean interior, and ocean mass transport by mesoscale eddies is comparable in magnitude with that of the wind-driven and thermohaline circulations (Richardson 1983; Wyrtki et al. 1976; Zhang et al. 2014). Although this study captured various SSEs with differing spatiotemporal scales, it remains unclear what role they play and whether they are as important as SE. To elucidate this, we integrated EKE vertically along the vertical extension of the SE and SSE at each time step during 1993-2013 and, then, calculated an average. As described previously, SE reflects eddies that have strong signals in the uppermost vertical layer of the model and that extend to depths of dozens or even hundreds of meters. The term SSE refers to those eddies whose entire body is located below depths of at least $45 \mathrm{~m}$. Given the large values of kinetic energy in the Kuroshio extension, and to depict the
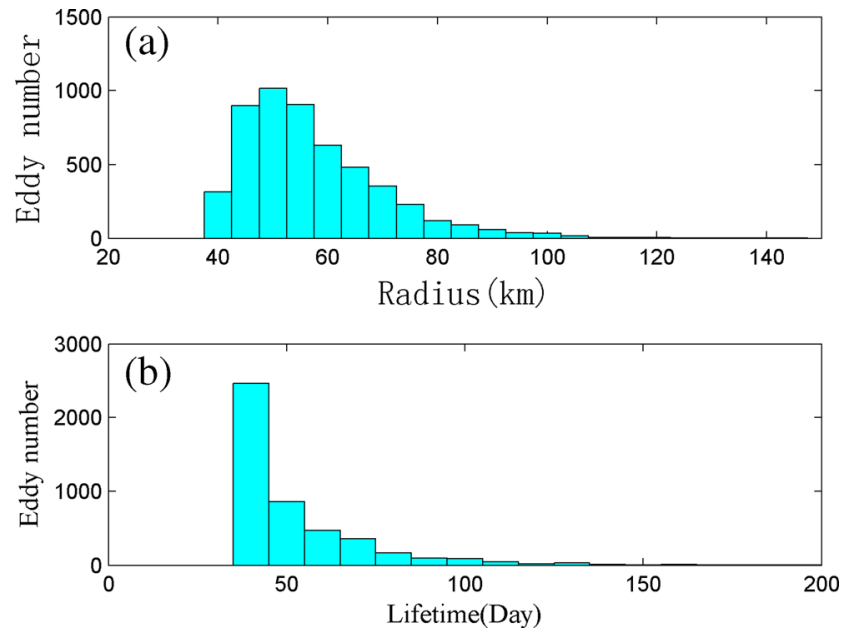

Fig. 10 Distribution of average (a) radius and (b) lifetime of all the detected subsurface eddies with lifetime $\geq 30$ days characteristics of the spatial distribution more intuitively, the logarithm of integral EKE is plotted in Fig. 7. A remarkable feature is that the mean energy of SSE is comparable in magnitude with SE. In the region of the Kuroshio Current and its extension, the energy of SSE is considerable and comparable with that of SE, which means that SSE and SE are of equal importance regionally. To the east of The Philippines, the kinetic energy of SSE is prominent, while there is little kinetic energy associated with SE. Previous research has shown that at least two groups of SSEs are found by subsurface mooring near the Philippine coast; the dominate period of SSEs is about 50-80 days (Chiang et al. 2015). These SSEs may be related to the instability of currents and complex topography as is the case in many other parts of the ocean. In addition, it is worth noting that although the frequency of SSE is very small along the equator, eddy energy is reasonably high, which could reflect deep SSE and large amounts of EKE there.

\subsection{Subsurface eddy statistics}

We tracked SSE at different depth levels and analyzed their properties based on the OFES data. Here, properties of SSE at the depth of $404 \mathrm{~m}$ (about $400 \mathrm{~m}$ ) are considered because most of the undercurrents in the northwestern Pacific Ocean cross this depth. Overall, 2569 SSAEs and 2099 SSCEs were detected in the northwestern Pacific during 1993-2013, which confirms the strong tendency for SSE to be anticyclonic.

Tracks of SSE with different lifespan (30,60, 90, and 120 days) are shown in Fig. 8a-d, although only those SSEs with displacement $>2^{\circ}$ are shown for clarity. It can be seen that some long-lived SSE exhibit longitudinal displacement of $15^{\circ}$. The numbers of SSAE and SSCE are indicated in the upper left corner of each panel. The predominance of anticyclonic SSE is evident with ratios between the quantities of SSCE and SSAE of 76, 66, 59, and 69\% illustrated in Fig. 8a-d, respectively. Two 

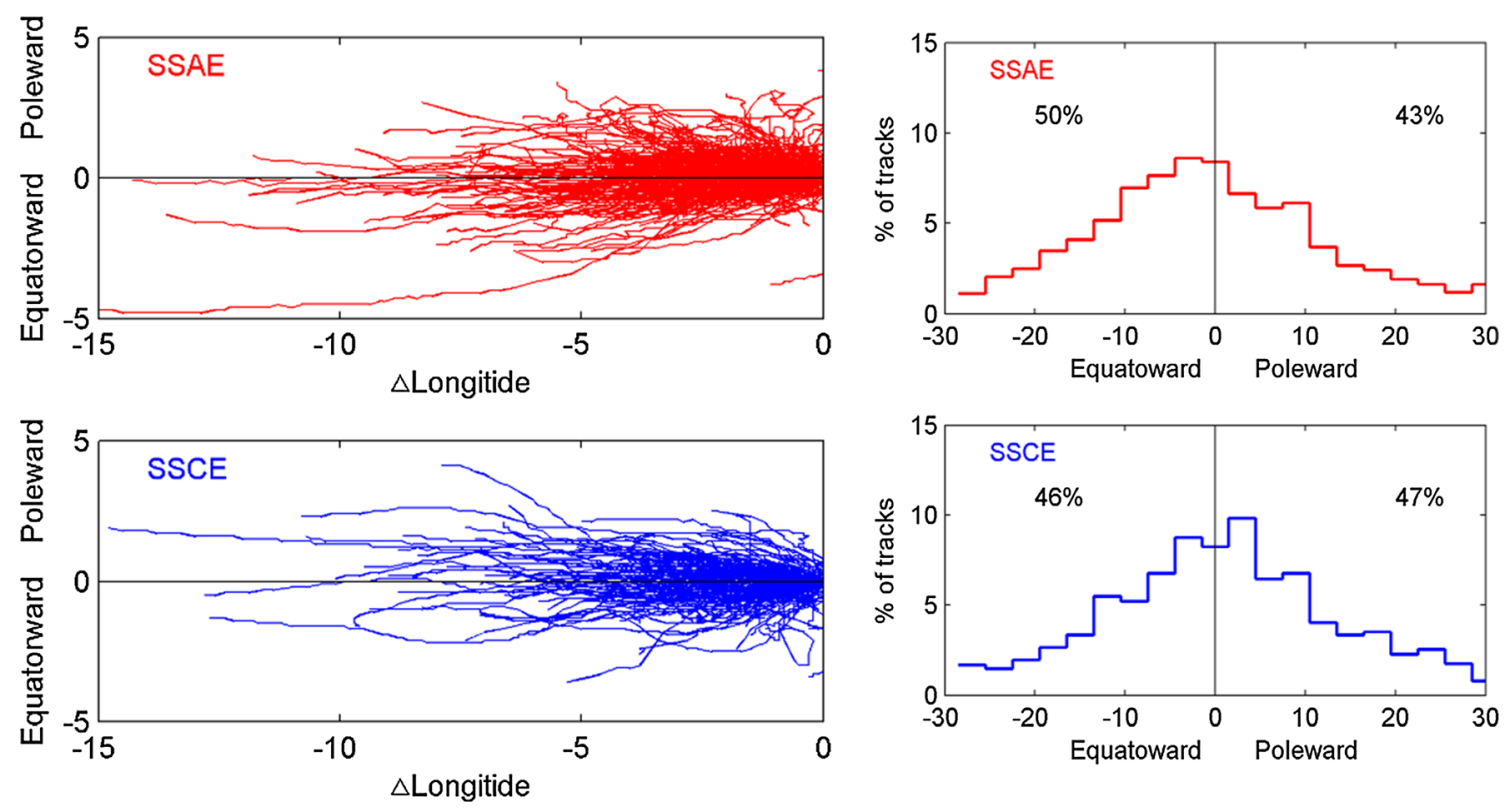

Fig. 11 Propagation characteristics of subsurface anticyclonic eddies (SSAEs) and subsurface cyclonic eddies (SSCEs) at a depth of about $400 \mathrm{~m}$ with lifetime $>60$ days. (left) Trajectories of SSAE and SSCE

relative to location of origin and (right) histograms of the mean propagation angle relative to due west

latitudinal bands $\left(9-17^{\circ} \mathrm{N}\right.$ and $\left.23-32^{\circ} \mathrm{N}\right)$ with high density of SSE can be observed, which generally correspond with the frequency of SSE (Fig. 6b) introduced in Section 4.1. It is worth noting that although SSEs exist in the region of the Kuroshio extension (Fig. 6b), only a few tracks can be found at about $400 \mathrm{~m}$ (Fig. 8). The reason for this might be that SSEs in this region occur at depths above or below $400 \mathrm{~m}$ or that their lifetime and transportation distance are too short to be counted. Although tracks of SSE with lifetime $<60$ days can be found in great numbers to the east of The Philippines, there are almost no SSE with lifespan $>120$ days. A census of the locations of origin of SSE in every $2^{\circ} \times 2^{\circ}$ region during 1993-2013 is shown in Fig. 9a. The coastal region east of The Philippines is shown as an important place of origin of SSE (i.e., > 15 SSEs were generated in each $2^{\circ} \times 2^{\circ}$ bin). In addition, it is evident that SSAEs have considerable numeric superiority over SSCEs in lower latitudes, i.e., from the equator to $17^{\circ} \mathrm{N}$ (Fig. $9 \mathrm{~b}$ ).

The scale of SSE is defined as the radius of a circle with area equal to the corresponding closed $\mathrm{W}_{0}$ contour. The mean radius of SSE is about $60 \mathrm{~km}$, and the scale of the majority of SSE is within the range at $40 \mathrm{~km}<$ radius $<70 \mathrm{~km}$, although several extraordinarily large SSEs with radius $>100 \mathrm{~km}$ were also detected. A histogram of the lifetimes of the tracks of SSE is presented in Fig. 10b. A total of $72 \%$ of SSEs can persist for 40 50 days and that the maximum survival time of SSEs is up to 150 days. The average survival time of SSAE and SSCE is 50 and 45 days, respectively. Overall, 102 SSAEs and 52 SSCEs survived longer than 100 days, which means that SSAEs are more likely than SSCEs to survive for longer periods.

Trajectories of SSE referenced to a common starting point are shown in Fig. 11(left). Generally, SSAEs have slight tendency for equatorward deflection, i.e., about $50 \%$ of SSAEs show equatorward deflection during their lifetime, while $43 \%$ are deflected poleward. Conversely, SSCEs show no obvious tendency of deflection (Fig. 11(right)). About 10 and $6 \%$ of SSAEs and SSCEs, respectively, propagated purely zonally $\left( \pm 1^{\circ}\right)$. We estimated propagation speeds by tracing the centroids of SSE along the trajectories as a function of time. Overall, the propagation speed of SSE shows a fluctuating trend of decrease as latitude increases, i.e., from $10.5 \mathrm{~cm} / \mathrm{s}$ near the equator to $3.0-4.0 \mathrm{~cm} / \mathrm{s}$ at $60^{\circ} \mathrm{N}$. The mean speed of all SSE is $6.6 \mathrm{~cm} / \mathrm{s}$. In the region of the Kuroshio extension, SSCE move slightly faster than SSAE (Fig. 12).

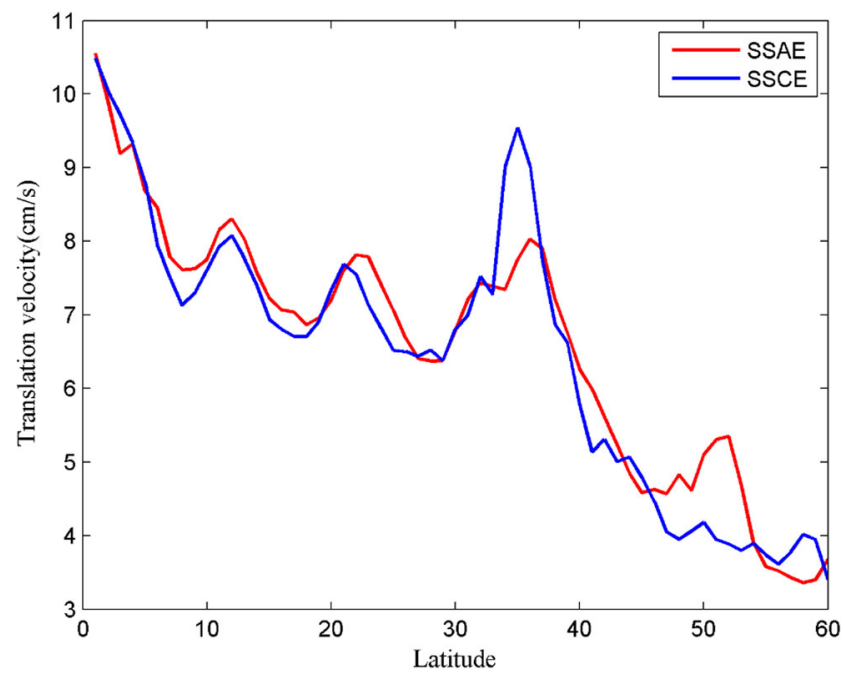

Fig. 12 Latitudinal variation of the average westward propagation speed $(\mathrm{cm} / \mathrm{s})$ of subsurface anticyclonic eddies (SSAE; red lines) and subsurface cyclonic eddies (SSCE; blue lines) 
Fig. 13 Distribution of nonlinearity parameter of subsurface anticyclonic eddies (SSAE; left) and subsurface cyclonic eddies (SSCE; right). The nonlinearity parameter is the ratio between swirl velocity and propagation speed

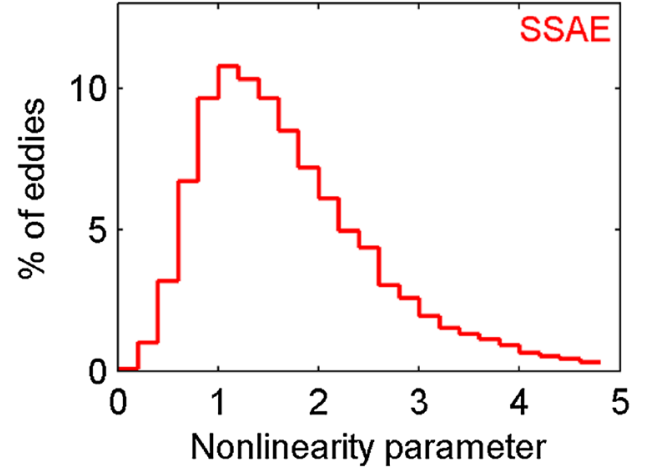

A common measure of the nonlinearity of eddies is the $u / c$ ratio, where $u$ is the average rotational speed and $c$ is the translation speed. Eddies characterized by a value of $u / c>1$ can trap fluid in their interior and transport water properties, such as heat, potential vorticity, and biogeochemical characteristics (Chelton et al. 2007, 2011). We calculated the nonlinearity parameter at each time step along each eddy track, and, then, we conducted statistical analysis. The distribution of the nonlinearity parameter for SSAE and SSCE is shown in Fig. 13a,b, respectively. The nonlinearity parameter ranges from 0 to 5 with about 78 and $79 \%$ of SSAE and SSCE, respectively, exceeding the value of 1 . About $89 \%$ (37\%) of tracked SSEs are nonlinear for at least half (all) their lifetime.

\section{Summary}

This study investigated the characteristics of SSE in the northwestern Pacific Ocean using OFES data. The $\mathrm{O}-\mathrm{W}$ method was used to detect eddies from the velocity field of the OFES data. Subsequently, the spatial distribution of all eddies (including SE and SSE) at each time step of the model data was determined. We extracted time series of vertical eddy distribution from the surface to the depth of about $2000 \mathrm{~m}$ at each grid point, and we estimated the frequency of occurrence of SE and SSE. Comparison of model output and altimeter observations indicated that the model data and our detection algorithm could satisfactorily reproduce eddy activities. A census of SSE at the depth of about $400 \mathrm{~m}$ revealed the characteristics of both anticyclonic and cyclonic eddies after eddy tracking.

In general, SSEs were found to exist widely in certain areas, e.g., the Kuroshio extension region, latitudinal band between $9^{\circ} \mathrm{N}$ and $17^{\circ} \mathrm{N}$, and to the east of the Ryukyu Islands, where the frequency of SSE was about 10, 16, and $8 \%$, respectively. Comparison of the frequency of occurrence of SSAE and SSCE revealed that while the STCC is known for abundant SE, the occurrence of SSE in this region is rare. Conversely, to the east of The Philippines, relatively few SEs occur, whereas there are frequent SSEs. The identified SSEs were used to evaluate the kinetic energy contained in SSE, which we found to be comparable in magnitude to that of SE. In region such as to the east of The Philippines and in latitudinal band $9^{\circ}-17^{\circ} \mathrm{N}$, the kinetic energy of SSE was found even larger. The tracks of SSE revealed their propagation characteristics. Most of the detected SSE tended to be anticyclonic. The average radius and lifespan of the SSE were determined as about $60 \mathrm{~km}$ and 50 days, respectively. Most of the observed SSEs were found nonlinear, which means that SSE can have considerable impact in the movement of heat and mass transport within the subsurface layer, especially in some regions with abundant SSE. The dynamical mechanism of SSE is complex, and it is often related to the regional background circulation, water mass characteristics, and/or topographic boundaries (Hormazabal et al. 2013; Nan et al. 2017; Takikawa et al. 2005).

Previous research has tended to focus on SE, and the importance of SSE has been underestimated, despite the considerable kinetic energy they contain. Although not visible at the surface, SSE with large spatial structure and long lifetime can accelerate the mixing and exchange of intermediate water. In this research, only eddies with large spatial scale and regular shape were detected, which could have introduced some uncertainty in the identification process and led to underestimation of the number of SSE. Because in situ data of SSE are scarce, model data constitute the only practical resource with which to reveal the characteristics of SSE. The census of the properties of SSE presented here using the model output represents the first step in our analysis of SSE. The results will be verified in future work when additional in situ observational data of eddies become available. Furthermore, the formation mechanisms, vertical structure, and transport of SSE in different regions, which were not investigated here, will be pursued in our future studies.

Acknowledgments We are grateful to $\mathrm{H}$. Sasaki and colleagues from the Earth Simulator for assistance in processing the Oceanic General Circulation Model for the Earth Simulator output and to the Segment Sol multi-missions d'ALTimetrie, d'Orbitograpie et de localization précise/Data Unification and Altimeter Combination System (DUACS) for the altimeter products distributed by the Archiving, Validation, and 
Interpolation of Satellite Oceanographic program. The 4th eddy dataset produced by the Collecte Localisation Satellites/DUACS team is available from http://wombat.coas.oregonstate.edu/eddies/index.

Funding information This work was jointly supported by the National Natural Science Foundation of China (41676005), Global Climate Changes and Air-Sea Interaction Program (GASI-IPOVAI-01-06), Chinese Academy of Sciences (CAS) "Huiquan Scholar," Youth Innovation Promotion Association of CAS, CAS Interdisciplinary Innovation Team, and NSFC Innovative Group Grant (Project No. 41421005).

Open Access This article is distributed under the terms of the Creative Commons Attribution 4.0 International License (http:// creativecommons.org/licenses/by/4.0/), which permits unrestricted use, distribution, and reproduction in any medium, provided you give appropriate credit to the original author(s) and the source, provide a link to the Creative Commons license, and indicate if changes were made.

\section{References}

Andrade I, Hormazabal S, Combes V (2014) Intrathermocline eddies at the Juan Fernandez Archipelago, southeastern Pacific Ocean. Lat Am J Aquat Res 42(4):888-906. https://doi.org/10.3856/vol42issue4-fulltext-14

Aoki S, Hariyama M, Mitsudera H, Sasaki H, Sasai Y (2007) Formation regions of subantarctic Mode Water detected by OFES and Argo profiling floats. Geophys Res Lett 34(10). https://doi.org/10.1029/ $2007 \mathrm{gl} 029828$

Chaigneau A, Eldin G, Dewitte B (2009) Eddy activity in the four major upwelling systems from satellite altimetry (1992-2007). Prog Oceanogr 83(1-4):117-123. https://doi.org/10.1016/j.pocean.2009. 07.012

Chaigneau A, Le Texier M, Eldin G, Grados C, Pizarro O (2011) Vertical structure of mesoscale eddies in the eastern South Pacific Ocean: a composite analysis from altimetry and Argo profiling floats. J. Geophys. Res.-Oceans 116(16). https://doi.org/10.1029/ $2011 \mathrm{jc} 007134$

Chang Y-L, Oey L-Y (2014) Analysis of STCC eddies using the OkuboWeiss parameter on model and satellite data. Ocean Dyn 64(2):259 271. https://doi.org/10.1007/s10236-013-0680-7

Chelton DB, Schlax MG, Samelson RM, de Szoeke RA (2007) Global observations large oceanic eddies. Geophys Res Lett 34:L15606. https://doi.org/10.1029/2007GL030812

Chelton DB, Schlax MG, Samelson RM (2011) Global observations of nonlinear mesoscale eddies. Prog Oceanogr 91(2):167-216. https:// doi.org/10.1016/j.pocean.2011.01.002

Chen J, Qu TD, Sasaki YN, Schneider N (2010) Anti-correlated variability in subduction rate of the western and eastern North Pacific Oceans identified by an eddy-resolving ocean GCM. Geophys Res Lett 37:6. https://doi.org/10.1029/2010gl045239

Chiang T-L, Qu T (2013) Subthermocline eddies in the Western Equatorial Pacific as shown by an eddy-resolving OGCM. J Phys Oceanogr 43(7):1241-1253. https://doi.org/10.1175/jpo-d-12-0187. 1

Chiang TL, Wu CR, Qu TD, Hsin YC (2015) Activities of 50-80 day subthermocline eddies near the Philippine coast. J. Geophys. Res.Oceans 120(5):3606-3623. https://doi.org/10.1002/2013jc009626

Colas F, McWilliams JC, Capet X, Kurian J (2012) Heat balance and eddies in the Peru-Chile current system. Clim Dyn 39(1-2):509 529. https://doi.org/10.1007/s00382-011-1170-6
Collins CA, Margolina T, Rago TA, Ivanov L (2013) Looping RAFOS floats in the California Current System. Deep-Sea Res. Part II-Top. Stud. Oceanogr. 85:42-61. https://doi.org/10.1016/j.dsr2.2012.07. 027

Combes V, Hormazabal S, Di Lorenzo E (2015) Interannual variability of the subsurface eddy field in the Southeast Pacific. J. Geophys. Res.Oceans 120(7):4907-4924. https://doi.org/10.1002/2014jc010265

Gordon AL, Giulivi CF, Lee CM, Furey HH, Bower A, Talley L (2002) Japan/East Sea intrathermocline eddies. J Phys Oceanogr 32(6): 1960-1974. https://doi.org/10.1175/1520-0485(2002)032<1960: jesie $>2.0 . c 0 ; 2$

Gordon AL, Shroyer E, Murty VSN (2017) An intrathermocline eddy and a tropical cyclone in the Bay of Bengal. Sci Rep 7. https://doi.org/10. 1038/srep46218

Hormazabal S, Combes V, Morales CE, Correa-Ramirez MA, Di Lorenzo E, Nunez S (2013) Intrathermocline eddies in the coastal transition zone off central Chile (31-41 degrees S). J Geophys Res-Oceans 118(10):4811-4821. https://doi.org/10.1002/jgrc.20337

$\mathrm{Hu}$ D, Cui M (1989) The western boundary current in the far-western Pacific Ocean. In: Picaut J, Lukas R, Delcroix T (eds) Proceedings of Western Pacific International Meeting and Workshop on TOGACOARE, May 24-30, 1989, Noum ea, New Caledonia. Inst. Fr. de Rech. Sci. pour le De ev. en Coop, Noum ea, pp 123-134

Hu D, Cui M, Qu T, Li Y (1991) A subsurface northward current off Mindanao identified by dynamic calculation. In: Takano K (ed) Oceanography of Asian marginal seas, Elsevier oceanography series, vol 54. Elsevier, Amsterdam, pp 359-365. https://doi.org/10. 1016/S0422-9894(08)70108-9

Isern-Fontanet J, Garcia-Ladona E, Font J (2003) Identification of marine eddies from altimetric maps. J Atmos Ocean Technol 20(5):772778. https://doi.org/10.1175/1520-0426(2003)20<772:iomefa $>2.0$. co; 2

Isern-Fontanet J, Font J, Garcia-Ladona E, Emelianov M, Millot C, Taupier-Letage I (2004) Spatial structure of anticyclonic eddies in the Algerian basin (Mediterranean Sea) analyzed using the OkuboWeiss parameter. Deep-Sea Res Part II-Top Stud Oceanogr 51(2526):3009-3028. https://doi.org/10.1016/j.dsr2.2004.09.013

Isern-Fontanet J, Garcia-Ladona E, Font J (2006) Vortices of the Mediterranean Sea: an altimetric perspective. J Phys Oceanogr 36(1):87-103. https://doi.org/10.1175/jpo2826.1

Johnson GC, McTaggart KE (2010) Equatorial Pacific 13 degrees C water eddies in the eastern subtropical South Pacific Ocean. J Phys Oceanogr 40(1):226-236. https://doi.org/10.1175/2009jpo4287.1

Kurian J, Colas F, Capet X, McWilliams JC, Chelton DB (2011) Eddy properties in the California Current System. J Geophys Res-Oceans 116. https://doi.org/10.1029/2010jc006895

Masumoto $\mathrm{Y}$ et al (2004) A fifty-year eddy-resolving simulation of the world ocean - preliminary outcomes of OFES (OGCM for the Earth Simulator). J Earth Simulator 1:35-56

McDowell SE, Rossby HT (1978) Mediterranean water-intense mesoscale eddy of Bahamas. Science 202(4372):1085-1087. https://doi. org/10.1126/science. 202.4372 .1085

McWilliams JC (1985) Submesoscale, coherent vortices in the ocean. Rev Geophys 23(2):165-182. https://doi.org/10.1029/ RG023i002p00165

Nan F, Yu F, Wei C, Ren Q, and Fan C (2017) Observations of an extralarge subsurface anticyclonic eddy in the Northwestern Pacific subtropical gyre. https://doi.org/10.4172/2155-9910.1000234

Nauw JJ, van Aken HM, Lutjeharms JRE, and de Ruijter WPM (2006) Intrathermocline eddies in the southern Indian Ocean. J Geophys Res-Oceans 111(C3):14. https://doi.org/10.1029/2005jc002917

Oka E, Toyama K, Suga T (2009) Subduction of North Pacific central mode water associated with subsurface mesoscale eddy. Geophys Res Lett 36:4. https://doi.org/10.1029/2009g1037540 
Okubo A (1970) Horizontal dispersion of floatable particles in vicinity of velocity singularities such as convergence. Deep-Sea Res 17(3):445. https://doi.org/10.1016/0011-7471(70)90059-8

Pasquero C, Provenzale A, Babiano A (2001) Parameterization of dispersion in two-dimensional turbulence. J Fluid Mech 439:279-303

Pelland NA, Eriksen CC, Lee CM (2013) Subthermocline eddies over the Washington continental slope as observed by seagliders, 2003-09. J Phys Oceanogr 43(10):2025-2053. https://doi.org/10.1175/jpo-d12-086.1

Qiu B (1999) Seasonal eddy field modulation of the North Pacific subtropical countercurrent: TOPEX/Poseidon observations and theory. J Phys Oceanogr 29(10):2471-2486. https://doi.org/10.1175/15200485(1999)029<2471:sefmot>2.0.co;2

Qiu B, Chen S, Rudnick DL, Kashino Y (2015) A new paradigm for the North Pacific subthermocline low-latitude Western boundary current system. J Phys Oceanogr 45(9):2407-2423. https://doi.org/10. 1175/jpo-d-15-0035.1

Qu TD, Chiang TL, Wu CR, Dutrieux P, Hu DX (2012) Mindanao current/undercurrent in an eddy-resolving GCM. J. Geophys. Res.Oceans 117(16). https://doi.org/10.1029/2011jc007838

Richardson PL (1983) Eddy kinetic-energy in the North-Atlantic from surface drifters. J. Geophys. Res.-Oceans 88(NC7):4355-4367. https://doi.org/10.1029/JC088iC07p04355

Richardson PL, Bower AS, Zenk W (2000) A census of Meddies tracked by floats. Prog Oceanogr 45(2):209-250. https://doi.org/10.1016/ s0079-6611(99)00053-1

Sasaki H, Nonaka M, Masumoto Y, Sasai Y, Uehara H, Sakuma H (2008) An eddy-resolving hindcast simulation of the Quasiglobal Ocean from 1950 to 2003 on the earth simulator. In: Hamilton K, Ohfuchi W (eds) chapter 10High resolution numerical modelling of the atmosphere and ocean. Springer, New York, pp 157-185

Shapiro GI, Meschanov SL (1991) Distribution and spreading of red-sea water and salt lens formation in the northwest Indian-ocean. DeepSea Res Parta-Oceanogr Res Pap 38(1):21-34. https://doi.org/10. 1016/0198-0149(91)90052-h
Takikawa T, Ichikawa H, Ichikawa K, Kawae S (2005) Extraordinary subsurface mesoscale eddy detected in the southeast of Okinawa in February 2002. Geophys Res Lett 32(17):4. https://doi.org/10. 1029/2005gl023842

Thomsen S, Kanzow T, Krahmann G, Greatbatch RJ, Dengler M, Lavik G (2016) The formation of a subsurface anticyclonic eddy in the Peru-Chile Undercurrent and its impact on the near-coastal salinity, oxygen, and nutrient distributions. J. Geophys. Res.-Oceans 121(1): 476-501. https://doi.org/10.1002/2015jc010878

Weiss J (1991) The dynamics of enstrophy transfer in 2-dimensional hydrodynamics. Physica D 48(2-3):273-294. https://doi.org/10. 1016/0167-2789(91)90088-q

Williams S, Petersen M, Bremer P-T, Hecht M, Pascucci V, Ahrens J, Hlawitschka M, Hamann B (2011) Adaptive extraction and quantification of geophysical vortices. IEEE Trans Vis Comput Graph 17: 2088-2095. https://doi.org/10.1109/TVCG.2011.162

Wyrtki K, Magaard L, Hager J (1976) Eddy energy in oceans. J Geophys Res Oceans Atmos 81(15):2641-2646. https://doi.org/10.1029/ JC081i015p02641

Yang G, Wang F, Li YL, Lin PF (2013) Mesoscale eddies in the northwestern subtropical Pacific Ocean: statistical characteristics and three-dimensional structures. J. Geophys. Res.-Oceans 118(4): 1906-1925. https://doi.org/10.1002/jgrc.20164

Zhang ZG, Wang W, Qiu B (2014) Oceanic mass transport by mesoscale eddies. Science 345(6194):322-324. https://doi.org/10.1126/ science. 1252418

Zhang Z, Li P, Xu L, Li C, Zhao W, Tian J, Qu T (2015) Subthermocline eddies observed by rapid-sampling Argo floats in the subtropical northwestern Pacific Ocean in Spring 2014. Geophys Res Lett 42(15):6438-6445. https://doi.org/10.1002/2015gl064601

Zhang ZG, Zhang Y, Wang W (2017) Three-compartment structure of subsurface-intensified mesoscale eddies in the ocean. J. Geophys. Res.-Oceans 122(3):1653-1664. https://doi.org/10.1002/ $2016 \mathrm{jc} 012376$ 